\title{
A new portable ventilation system for basic life support 一次救命のための新たな携帯型人工呼吸器の開発
}

\author{
Tomokazu KAWAMURA and Keitaro HASHIMOTO \\ Department of Pharmacology, Interdisciplinary Graduate School of Medicine and Engineering, \\ University of Yamanashi, 1110, Shimogato,Tamaho, Nakakoma,Yamanashi,409-3898 Japan \\ TEL: x81-46-219-1921 FAX: x81-46-219-1921 e-mail:k-tomo51@jcom.home.ne.jp
}

Shuji SHIMAZAKI

Department of Traumatology and Critical Care Medicine, Kyorin University School of Medicine, 6-20-2, Shinkawa, Mitaka, Tokyo,181-8611 Japan

TEL: x81-422-47-5511 FAX:x81-422-42-4866 e-mail:shimazak@kyorin-u.ac.jp

Kiyoyuki YAMAZAKI and Naoaki KANAI

Department of Bio-Medical Engineering, School of High-Technology for Human Welfare, Tokai University,317, Nishino, Numadu, Shizuoka, 410-0395 Japan

TEL: x81-55-968-1211(EX.4523) FAX:x81-55-968-1156 e-mail: nkanai@wing.ncc.u-tokai.ac.jp

( Received 7, February 2006 Accepted 10, April 2006 )

Mouth-to-mouth resuscitation is believed to be a quick, effective method for providing oxygen to a victim. The International Guidelines of 2000 have recommended reducing the risk of gastric inflation during mouth-to-mouth ventilation by delivering slow breaths at the lowest tidal volume that would still raise the chest visibly with each ventilation. For mouth-to-mouth ventilation in most adults, the tidal volume would be approximately $10 \mathrm{ml} / \mathrm{kg}$ (ca. 700-1000 ml). It should be delivered over $2 \mathrm{~s}$. Can however, an appropriate amount be blown in even if there is no special instruction when an untrained citizen suddenly encounters an accident? We investigated the mean tidal volume during mouth-to-mouth resuscitation by untrained citizens, and it was ca. $800 \mathrm{ml}$, which corresponds to the recommended value of the current guidelines. In the mouth-to-mouth resuscitation, the composition of the expired air that the rescuer administers to the victim was $\mathrm{PO}_{2}$ and $\mathrm{PCO}_{2}$ of $115 \pm 1 \mathrm{mmHg}$ and $32 \pm 1 \mathrm{mmHg}$ when the tidal volume was $500 \mathrm{ml}$. When the tidal volume was $1 \mathrm{l}, \mathrm{PO}_{2}$ and $\mathrm{PCO}_{2}$ were $120 \pm 1 \mathrm{mmHg}$ and $29 \pm 1 \mathrm{mmHg}$, respectively $(\mathrm{N}=10)$. Moreover, when the ventilation experiment was done to the animal (beagle), the following results were shown $(\mathrm{N}=7)$. The amount of ventilation was ca. $20 \mathrm{ml} / \mathrm{kg}$, and 12 breaths per minute. In addition, arterial $\mathrm{PaO}_{2}, \mathrm{PaCO}_{2}$, and $\mathrm{pH}$ were measured. Consequently, after mouth-to-mouth ventilation, $\mathrm{PaO}_{2}$ decreased to $71 \pm 1 \mathrm{mmHg}$ (normal value $=95-100 \mathrm{mmHg}$ ), $\mathrm{PaCO}_{2}$ increased to $54 \pm 2$ $\mathrm{mmHg}$ (normal value $=40 \mathrm{mmHg}$ ), and the $\mathrm{pH}$ became $7.27 \pm 0.02$. To improve the respiratory state after mouth-to-mouth ventilation, we developed a new Portable Ventilation System (PVS) to the improve ventilation efficiency and to alleviate the risk of infectious disease. By using PVS, the composition of inflow air of the mouth-to-mouth ventilation by rescuers was $\mathrm{PO}_{2} 139 \pm 2 \mathrm{mmHg}$ and $\mathrm{PCO}_{2} 15 \pm 1 \mathrm{mmHg}$ $(\mathrm{N}=10)$, when the tidal volume was $500 \mathrm{ml}$ and $\mathrm{PO}_{2}$ and $\mathrm{PCO}_{2}$ were $131 \pm 2 \mathrm{mmHg}$ and $19 \pm 1 \mathrm{mmHg}$, respectively when the tidal volume was $1 \mathrm{l}(\mathrm{N}=10)$. This ventilation experiment was performed on animals (beagle). After artificial ventilation with gas made by PVS, changes of arterial $\mathrm{PaO}_{2}, \mathrm{PaCO}_{2}$ and $\mathrm{pH}$ were improved to $84 \pm 2 \mathrm{mmHg}, 46 \pm 1 \mathrm{mmHg}$, and $7.37 \pm 0.01$, respectively $(\mathrm{N}=7)$. Consequently, results showed that the ventilation efficiency of the new PVS was higher than that for mouth-to-mouth ventilation.

Keywords : Mouth-to-mouth ventilation; PV System; Blood gas analysis 


\section{INTRODUCTION}

Fifty years since the introduction of modern cardiopulmonary resuscitation (CPR), we have witnessed many advances for respiratory arrest victims. Many studies ${ }^{1-4}$ have shown that mouth-to-mouth resuscitation is better than mouth-to-airway methods of artificial respiration with the chest-pressure arm-lift methods. In the 1960 s, it was shown that the above mentioned points are important aspects for resuscitation. ${ }^{5-7}$

In the resuscitation, the importance of early artificial respiration is clear. When artificial respiration is delayed or when other proper care (CPR, AED, etc.) is not at hand, the so-called "Chain of Survival" is broken. The actions taken during the first few minutes of an emergency are critical to a victim's survival. Resuscitation consists of basic life support (BLS) at the accident site and advanced life support (ALS) in the hospital. Artificial respiration by the bystander is an important part of BLS. The BLS that commences over 4 min after an accident is called Late BLS. The ALS that commences over 12 min after the cardio-respiratory arrest is called Late ALS. Eisenberg et al. ${ }^{8}$ reported that both Late BLS and Late ALS are fatal. In Seattle, U.S.A., the survival rate of patients who were administered BLS by a bystander within 4 min from an accident was $43 \%$. In contrast, the survival rate of patients in late BLS more than 4 min after an accident was $21 \%$. These results emphasize the importance of bystander CPR. However, citizens, even physicians, and nurses are reluctant to perform mouth-to-mouth ventilation. ${ }^{9-16}$ The most commonly stated reason for not performing mouth-to-mouth ventilation is fear of infectious diseases. The perceived risk of disease transmission during CPR has reduced the willingness of some laypersons to initiate mouth-to-mouth ventilation to unknown victims of cardiac arrest. If the rescuer is unwilling or unable to perform mouth-to-mouth ventilation, manual ventilation equipment such as a bag-mask system with valves or a mouth-to-mask can be used, but they are not easy to use for unskilled users.

For artificial respiration, an appropriate removal competence of carbon dioxide from the blood and an ability to add appropriate oxygen to arterial blood are required. Therefore, the discussion about the appropriate tidal volume in artificial respiration has continued for a long time. ${ }^{17-22} \mathrm{~A}$ new international guideline was introduced based on previous recommendations. ${ }^{23-29}$ The 1992 ECC Guidelines ${ }^{30}$ recommend that adult rescuers breathe a tidal volume of $800-1200 \mathrm{ml}$, delivered over 1-2 s. International Guidelines of 2000 recommended that to reduce the risk of gastric inflation during mouth-to-mouth ventilation by delivering slow breaths at the lowest tidal volume that would still raise the chest visibly with each ventilation. For mouth-to-mouth ventilation in most adults, this volume would be approximately $10 \mathrm{ml} / \mathrm{kg}$ (ca. $700-1000 \mathrm{ml}$ ) and should be delivered over $2 \mathrm{~s}$.

We developed a novel portable ventilation system (PVS) that bystanders can use quickly and effectively, compared to the mouth-to-mouth method in human and animal experiments.

The present PV systems are comprised of the following four parts as shown in Fig. 1: (a) a mask, (b) an intake and exhaust integrated valve, (c) a bellows, and (d) a mouthpiece. The bellows play the role of a "dead space" to provide more fresh-air content than mouth-to-mouth ventilation to patients (see Fig.1-(c)). The integrated valve also contributes to fresh air ventilation. As the bystander inspires air from the mouthpiece, room air is taken into the bellows through the intake portion of the integrated valve (see Fig.2-a). When the bystander expires, mixed air of the expired gas and room air would be provided for patients through the exhaust part of the integrated valve (see Fig.2-b). Expired gas from the patients is discharged separately by the integrated valve (see Fig.2-c). This system allows for efficient and sanitary ventilation.

(c) bellows

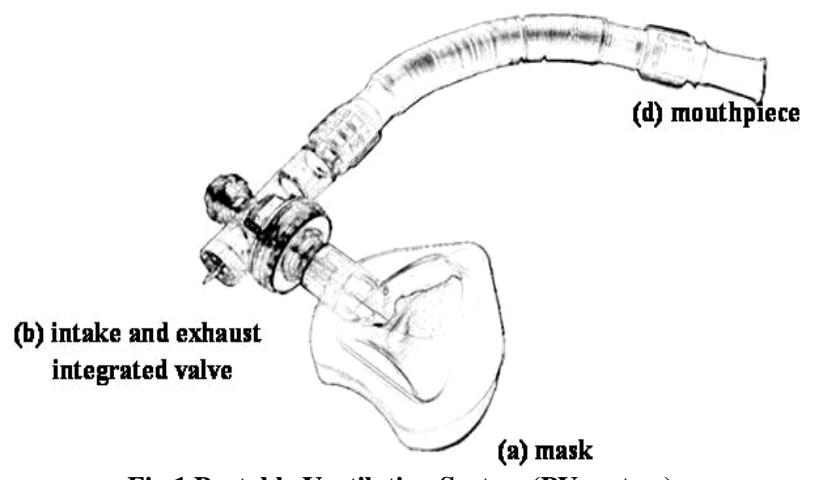

Fig.1 Portable Ventilation System (PV system)

The present PV system comprises four parts: (a) a mask, (b) an intake and exhaust integrated valve, (c) a bellows, and (d) a mouthpiece. 


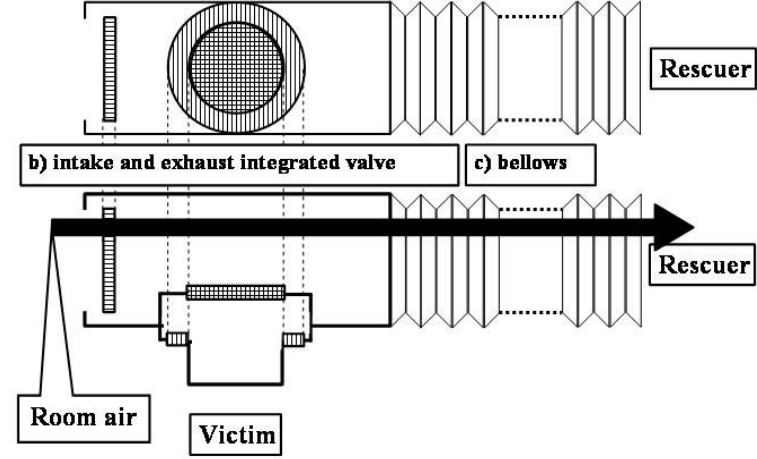

Fig. 2-a Intake and exhaust integrated valve First, a bystander inspired air from the mouthpiece; room air will be taken into the bellows through the intake portion of the integrated valve.

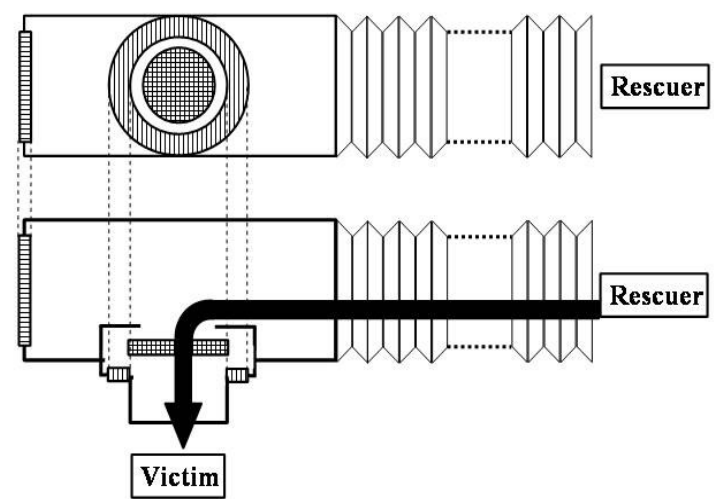

Fig. 2-b Intake and exhaust integrated valve When the bystander expires, mixed air of the expired gas and room air will provide for patients through the exhaust part of the integrated valve.

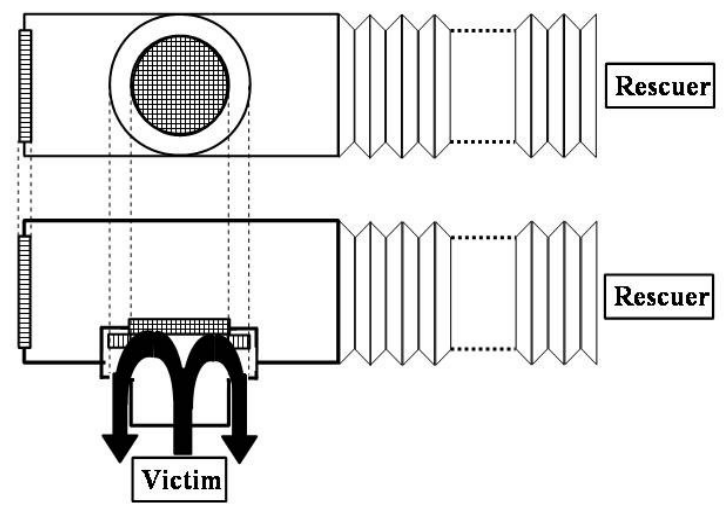

Fig. 2-c Intake and exhaust integrated valve Expired gas from the patients was discharged separately through the integrated valve.

\section{EXPERIMENTAL METHOD}

In practical situation such as disastens, the participation of untrained bystanders in BLS is important. So present experiments enrolled volunteers who had no experience in emergency resuscitation.

II-A. Investigation of mean tidal volume whenusing mouth-to-mouth resuscitation or PVS by untrained citizens

This experiment enrolled volunteers (18 males, 11 females) who had no experience in emergency resuscitation. The amount of the expired air that the general citizens blew into the patient was investigated when there was neither knowledge nor instruction concerning the revival. Minimum information (open the airway, tilt the head back, and provide rescue breathing) was given to volunteers. In addition, volunteers were made to perform artificial respiration by mouth-to-mouth breathing. In that case, there was no guidance as to the amount of ventilation. Volunteers were directed to perform artificial respiration 12 times per minute (one breath every $5 \mathrm{~s}$ ). The amount of the expired air was measured using a flow meter and training aids (Ambu). A similar experiment was done using PVS.

II-B. Comparison of gas composition of expired air between mouth-to-mouth ventilation and the PVS

This study was done to examine gas composition of the expired air when mouth-to-mouth ventilation was done. In addition, a similar experiment was done using PVS. The volunteers consisted of five men and five women. All were healthy adults. $\mathrm{PO}_{2}$ and the $\mathrm{PCO}_{2}$ of expired air were compared for mouth- to-mouth breathing and PVS ventilation. The expired air was gathered with mouth-to-mouth resuscitation as recommended in the International Guidelines 2000. However, a gathering method was devised for an impartial sampling shown in Fig.3. Under the procedure shown in Fig. 3, mouth-to-mouth and PVS ventilation were performed alternately. Each amount of expired gas was sampled separately in an air bag for $\mathrm{PO}_{2}$ and $\mathrm{PCO}_{2}$ analysis by OSCAR.

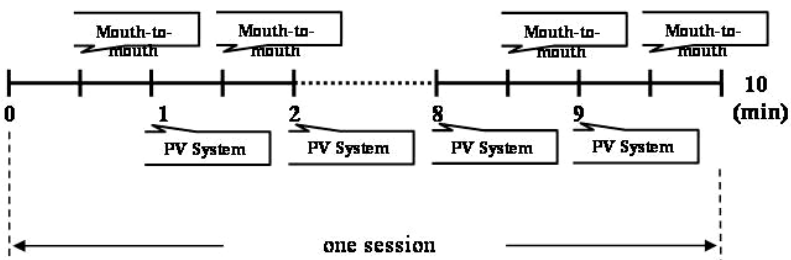

Fig. 3 Procedure of gas sampling

Expired air was gathered according to mouth-to-mouth resuscitation recommended in International Guidelines 2000. However, the collection method was devised for an impartial sampling. Under the procedure shown in Fig. 3, mouth-to-mouth and PVS ventilation were performed alternatively. Respective expired gases were sampled separately in air bags. 
II-C. Comparison of effects on arterial bloodgas between mouth-to-mouth ventilation and PVS in beagle dogs

Incubated and venous anesthetized beagles (females $\mathrm{n}=7$ mean weight $=9.5 \mathrm{~kg}$ ) controlled by a mechanical ventilator were used for the experiment. Ventilation was controlled using a respirator, and the direction to breathe in 12 times a minute (one breathe every $5 \mathrm{~s}$ ). The amount of ventilation was approximately $20 \mathrm{ml} / \mathrm{kg}$. Inspired gas was changed in the following order; (1) room air, (2) gas that corresponded to the expired air of the mouth-to-mouth ventilation, and (3) gas that corresponded to the expired air of the PVS. Animals were ventilated continuously for $12 \mathrm{~min}$ for each gas and $1 \mathrm{ml}$ of arterial blood was sampled every 3 min. Sampled blood was analyzed quantitatively for $\mathrm{PaO}_{2}, \mathrm{PaCO}_{2}, \mathrm{pH}, \mathrm{BE}$, and $\mathrm{SO}_{2}$ using Portable Clinical Analyzer i-STAT.

\section{RESULTS}

III-A. Mean tidal volume when using mouth-to-mouth ventilation or PVS by untrained citizens

The volume of expired air that the resuscitation-inexperienced citizens blew into the victim by mouth-to-mouth ventilation was 700-1000 ml (mean 840 $\pm 150 \mathrm{ml}$ ). Similarly, the amount of expired air that the inexperienced citizens for the resuscitation blew in to the victim by PVS was $600-900 \mathrm{ml}$ (mean $740 \pm 130 \mathrm{ml}$ ) (see Table 1).

Table 1. Comparison of mean tidal volume between Mouth-to-mouth method and the PV system in untrained participants

\begin{tabular}{|c|c|c|}
\hline & $\begin{array}{c}\text { Mouth-to-mouth } \\
(\mathrm{L})\end{array}$ & $\begin{array}{c}\text { PV System } \\
(\mathrm{L})\end{array}$ \\
\hline $\begin{array}{c}\text { Males } \\
(\mathrm{N}=18)\end{array}$ & $0.85 \pm 0.08$ & $0.77 \pm 0.07$ \\
\hline $\begin{array}{c}\text { Females } \\
(\mathrm{N}=11)\end{array}$ & $0.83 \pm 0.22$ & $0.70 \pm 0.18$ \\
\hline $\begin{array}{c}\text { Total } \\
(\mathrm{N}=29)\end{array}$ & $0.84 \pm 0.15$ & $0.74 \pm 0.13$ \\
\hline
\end{tabular}

III-B. Comparison of gas composition of expired air between mouth-to-mouth ventilation and the PVS

By mouth-to-mouth ventilation, when the tidal volume of the expired gas was $500 \mathrm{ml}, \mathrm{PO}_{2}$ and $\mathrm{PCO}_{2}$ were $115 \pm 1 \mathrm{mmHg}$ and $32 \pm 1 \mathrm{mmHg}$, respectively $(\mathrm{N}=10)$ and when the tidal volume was
$1 \mathrm{l}, \mathrm{PO}_{2}$ and $\mathrm{PCO}_{2}$ were $120 \pm 1 \mathrm{mmHg}$ and $29 \pm 1$ $\mathrm{mmHg}$, respectively $(\mathrm{N}=10)$. Artificial respiration that uses PVS allows the rescuer to send the victim the following composition of gas. When the tidal volume was $500 \mathrm{ml}, \mathrm{PO}_{2}$ and $\mathrm{PCO}_{2}$ were $139 \pm 2$ $\mathrm{mmHg}$ and $15 \pm 1 \mathrm{mmHg}$, respectively $(\mathrm{N}=10)$ and when the tidal volume was $1 \mathrm{l}, \mathrm{PO}_{2}$ and $\mathrm{PCO}_{2}$ were $131 \pm 2 \mathrm{mmHg}$ and $19 \pm 1 \mathrm{mmHg}$, respectively $(\mathrm{N}=10)$. When the tidal volume was adjusted to $800 \mathrm{ml}$ average tidal volume obtained above, $\mathrm{PO}_{2}$ and $\mathrm{PCO}_{2}$ of expired gas with mouth-to-mouth methods were $118 \pm 1 \mathrm{mmHg}$ and $30 \pm 1 \mathrm{mmHg}$, respectively and by the $\mathrm{PVS}, \mathrm{PO}_{2}$ and $\mathrm{PCO}_{2}$ were $134 \pm 2 \mathrm{mmHg}$ and $17 \pm 1 \mathrm{mmHg}$, respectively (see Fig.4 and 5).

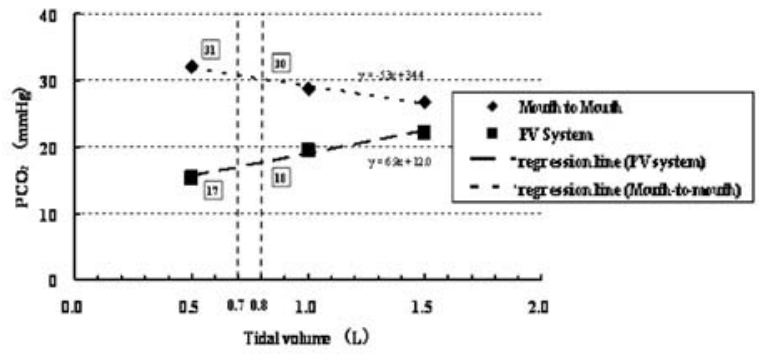

Fig.4 Relationship between tidal volume and PCO2 in Mouth-to-mouth method and the PV system For mouth- to-mouth breathing and the PVS, we examined the relation between the tidal volume and PCO2 included in rescuers' expired air. The vertical axis shows PCO2 (mmHg); the horizontal axis shows the tidal volume (l). When the tidal volume is $0.5 \mathrm{l}$, PCO2 in mouth-to-mouth breathing and PVS are, respectively, $32 \pm 1 \mathrm{mmHg}$, and $15 \pm 1 \mathrm{mmHg}(\mathrm{N}=10)$. When the tidal volume is $1.0 \mathrm{l}, \mathrm{PCO} 2$ in mouth-to-mouth breathing and PVS is, respectively, $29 \pm 1 \mathrm{mmHg}$, and $19 \pm 1 \mathrm{mmHg}$ $(\mathrm{N}=\mathbf{1 0})$.

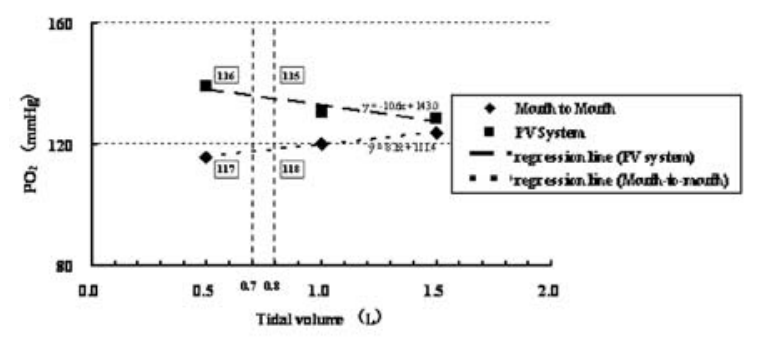

Fig.5 Relationship between tidal volume and PO2 in Mouth-to-mouth method and the PV system In mouth- to-mouth breathing and the PVS, we examined the relation between the tidal volume and $\mathrm{PO} 2$ included in rescuers' expired air. The vertical axis shows PO2 (mmHg), and the horizontal axis shows the tidal volume (l). When the tidal volume is $0.5 \mathrm{l}$, PO2 in mouth-to-mouth breathing and PVS is respectively $115 \pm 1 \mathrm{mmHg}$, and $139 \pm 2 \mathrm{mmHg}(\mathrm{N}=10)$. When the tidal volume is $1.0 \mathrm{l}, \mathrm{PO} 2$ in mouth-to-mouth breathing and PVS are, respectively, $120 \pm 1 \mathrm{mmHg}$, and $131 \pm 2 \mathrm{mmHg}(\mathrm{N}=10)$.

III-C. Comparison of effects on arterial blood gas between mouth-to-mouth ventilation and PVS

In beagles, mouth-to-mouth ventilation 
decreased $\mathrm{PaO}_{2}$ to $71 \pm 1 \mathrm{mmHg}$ (normal value $=$ 95-100 mmHg) and increased $\mathrm{PaCO}_{2}$ to $54 \pm 2$ $\mathrm{mmHg}$ (normal value $=40 \mathrm{mmHg}$ ), and the $\mathrm{pH}$ became $7.27 \pm 0.02$. Similarly, after artificial respiration using PVS, changes of $\mathrm{PaO}_{2}, \mathrm{PaCO}_{2}$, and $\mathrm{pH}$ were suppressed as mean $84.0 \pm 2 \mathrm{mmHg}$, $46 \pm 1 \mathrm{mmHg}$, and $7.37 \pm 0.01$, respectively $(\mathrm{N}=7)$ (see Fig.6-8).

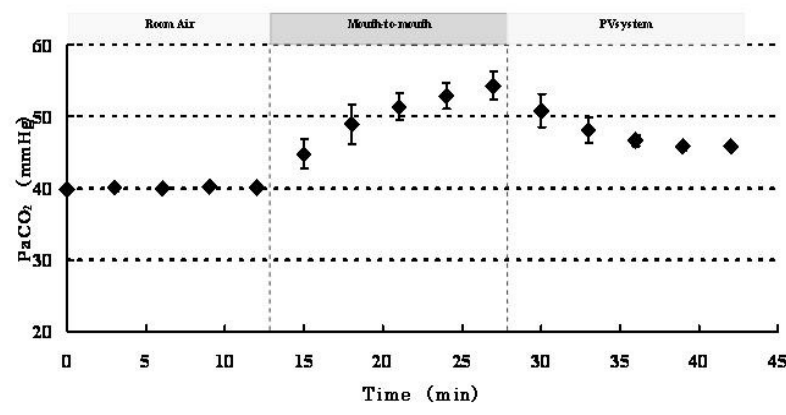

Fig.6 Effects of ventilation in each method on arterial blood gas (PaCO2) (beagle, $\mathrm{N}=7)($ mean \pm SD)

The vertical axis shows PaCO2 ( $\mathrm{mmHg}$ ); the horizontal axis shows the time (min). After mouth-to-mouth ventilation, $\mathrm{PaCO} 2$ increased to $54 \pm 2 \mathrm{mmHg}$ (normal value $=40 \mathrm{mmHg}$ ). Then, after artificial respiration using $\mathrm{PVS}$, changes of $\mathrm{PaCO} 2$ were suppressed: $46 \pm 1 \mathrm{mmHg}(\mathrm{N}=7)$.

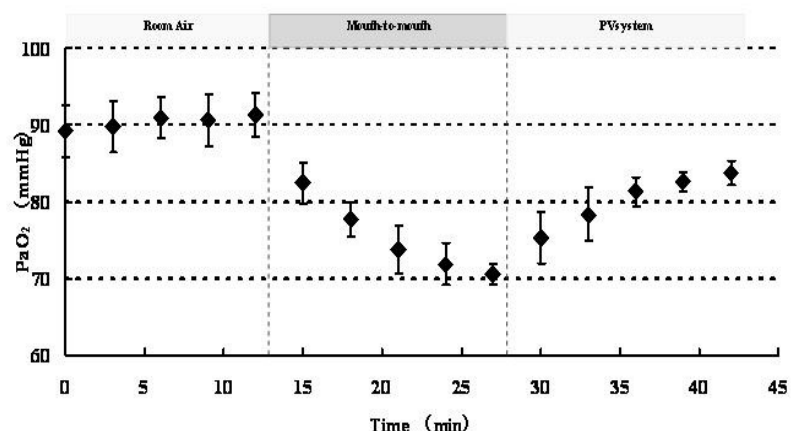

Fig.7 Effects of ventilation in each method on arterial blood gas (PaO2) (beagle, $\mathrm{N}=7)($ mean \pm SD)

The vertical axis shows $\mathrm{PaO} 2(\mathrm{mmHg})$; the horizontal axis shows the time (min). After mouth-to-mouth ventilation, $\mathrm{PaO} 2$ decreased to $71 \pm 1 \mathrm{mmHg}$ (normal value $=95-100 \mathrm{mmHg}$ ). Then, after the artificial respiration using PVS, changes of $\mathrm{PaO} 2$ were suppressed: $84 \pm 2 \mathrm{mmHg}(\mathrm{N}=7)$.

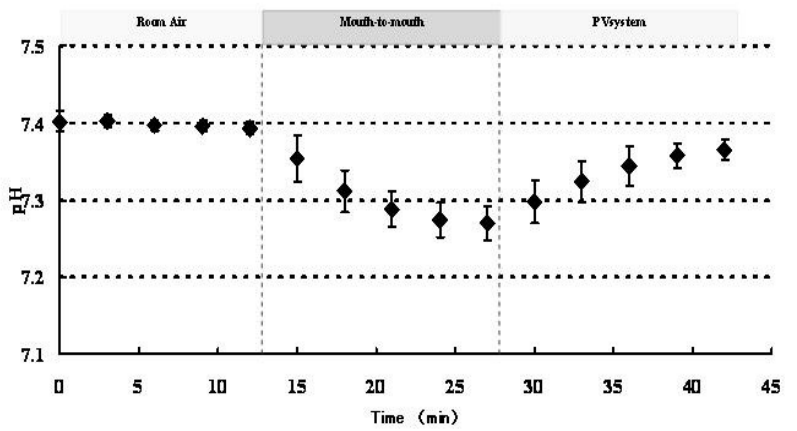

Fig.8 Effects of ventilation in each method on arterial blood gas (pH) (beagle, $\mathrm{N}=7)($ mean $\pm \mathrm{SD})$

The vertical axis shows $\mathrm{pH}$, and the horizontal axis shows the time (min). After mouth-to-mouth ventilation, the $\mathrm{pH}$ became $7.27 \pm 0.02$. Then, after the artificial respiration using PVS, the changes of $\mathbf{p H}$ were suppressed $7.37 \pm 0.01(\mathrm{~N}=7)$.

\section{DISCUSSION}

The need for new methods of CPR is not limited to adults with acute coronary syndrome (ACS) and strokes. Many victims of trauma, drowning, electrocution, suffocation, airway obstruction, drug intoxication, and the like may be saved by prompt $\mathrm{CPR}$, and an automated external defibrillator (AED). Prompt bystander CPR is crucial to all resuscitative efforts. ${ }^{31,} 32$ Victims' lifesaving rate out of the hospital vary widely in reports around the United States, in large metropolitan areas such as Chicago and New York, which have low rates of bystander CPR and longer call-to-shock intervals, of less than $5 \%$. $^{33,34}$

For mouth-to-mouth ventilation in most adults, the inflation volume would be ca. $10 \mathrm{ml} / \mathrm{kg}$ (ca. 700-1000 ml) and should be delivered over $2 \mathrm{~s}$. However, it was not known how much volume was inspired by citizens doing artificial respiration without using a flow meter. Our data shows that both average tidal volumes to the victim for whom the citizens had used mouth-to-mouth resuscitation or PVS were approximately $800 \mathrm{ml}$ (Table 1 ) and this is consistent with the recommended value of the current guidelines.

Our new PV system reduced $\mathrm{PCO}_{2}$ in expired gas by $40 \%$ (See Table 2, Figs. 4 and 5) and this is reflected in the animal data of the mean $\mathrm{PaCO}_{2}$ of blood gas analysis in the PVS, which was smaller by $8 \mathrm{mmHg}$ than that in a mouth-to-mouth equivalent gas condition. Mean $\mathrm{PaO}_{2}$ of blood gas analysis in the PV system was greater by 13 $\mathrm{mmHg}$ than that of the mouth-to-mouth equivalent gas condition (See Table 3, Figs. 6-8). These results show that the unfavorable effect of the mouth-to-mouth ventilation exerted on the living body is unexpectedly large and the. PVS can suppress this effect. The PVS has also the advantage of alleviating the risk of infectious disease. In addition to this ventilation efficiency of PVS over mouth-to-mouth ventilation, the PV system with artificial dead space will provide effective ventilation with easy operation for untrained bystanders.

Table 2 Composition of expired gases in respective methods $(\mathrm{N}=10)$

\begin{tabular}{|c|c|c|c|c|}
\hline \multirow{2}{*}{ TV(L) } & \multicolumn{2}{|c|}{ Mouth-to-mouth } & \multicolumn{2}{c|}{ PV system } \\
\cline { 2 - 5 } & $\begin{array}{c}\mathrm{PO}_{2} \\
(\mathrm{mmHg})\end{array}$ & $\begin{array}{c}\mathrm{PCO}_{2} \\
(\mathrm{mmHg})\end{array}$ & $\begin{array}{c}\mathrm{PO}_{2} \\
(\mathrm{mmHg})\end{array}$ & $\begin{array}{c}\mathrm{PCO}_{2} \\
(\mathrm{~mm} \mathrm{mg}\end{array}$ \\
\hline 0.5 & $115 \pm 1$ & $32 \pm 1$ & $139 \pm 2$ & $15 \pm 1$ \\
\hline 1.0 & $120 \pm 1$ & $29 \pm 1$ & $131 \pm 2$ & $19 \pm 1$ \\
\hline 1.5 & $123 \pm 1$ & $27 \pm 1$ & $128 \pm 1$ & $22 \pm 1$ \\
\hline
\end{tabular}


Table 3 Effects of ventilation in each method on arterial blood gas (beagle, $\mathrm{N}=7)($ mean \pm SD)

\begin{tabular}{|c|c|c|c|}
\hline & Room Air & Mouth-to-mouth & PV system \\
\hline PH & $7.39 \pm 0.01$ & $7.27 \pm 0.02$ & $7.37 \pm 0.01$ \\
\hline $\mathrm{PaCO}_{2}$ (mmHg) & $40 \pm 0$ & $54 \pm 2$ & $46 \pm 1$ \\
\hline $\mathrm{PaO}_{2}$ (mmHg) & $91 \pm 3$ & $71 \pm 1$ & $84 \pm 2$ \\
\hline
\end{tabular}

\section{ACKNOWLEDGMENTS}

We thank Mr. Yoshinobu Nagasawa for cooperating in the experiment used beagles.

\section{REFERENCES}

${ }^{1}$ Elam JO, Brown ES, John D. Elder. Artificial Respiration by Mouth-to-Mask Method. The New England Journal of Medicine 1954; 250: 18: 749-54.

${ }^{2}$ Peter Safar, Lourdes A. Escarraga, James O. Elam. A Comparison of The Mouth-to-Mouth and Mouth-to-Airway Methods of Artificial Respiration with The Chest-Pressure Arm-Lift Methods. The New England Journal of Medicine 1958; 258: 14: 671-7.

${ }^{3}$ Elam JO, Greene DG, Brown ES, Clements JA. Oxygen and carbon dioxide exchange and energy cost of expired air resuscitation. JAMA 1958; 167: 328-41.

${ }^{4}$ Gordon AS, Frye CW, Gittelson L, Sadove MS, Beattie EJ Jr. Mouth-to-Mouth Versus Manual Artificial Respiration for Children and Adults. JAMA 1958; 167: 3: 320-8.

${ }^{5}$ Kouwenhoven W, Jude JR, Knickerbocker GG. Closed-chest cardiac massage. 1960; 173: 1064-67.

${ }^{6}$ Safar P, Brown TC, Holtey WJ, Wilder RJ. Ventilation and Circulation with Closed-Chest Cardiac Massage in Man. JAMA 1961; 176: 7: 574-6

${ }^{7}$ Harris LC, Kirimli B, Safar P. Ventilation-Cardiac Compression Rates and Ratios in Cardiopulmonary Resuscitation. Anesthesiology 1967; 28: 5: 806-13.
${ }^{8}$ Eisenberg MS, Bergner L, Hallstrom A. Cardiac Resuscitation in the Community Importance of Rapid Provision and Implications for Program Planning. JAMA 1979; 241: 18: 1905-7.

${ }^{9}$ Ornato JP, Hallagan LF, McMahan SB, Peeples EH, Rostafinski AG. Attitudes of BCLS instructors about mouth-to-mouth resuscitation during the AIDS epidemic. Ann Emerg Med 1990; 19: 151-6.

${ }^{10}$ Brenner BE, Kauffman J. Reluctance of internists and medical nurses to perform mouth-to-mouth resuscitation. Arch Intern Med 1993; 153: 1763-9.

${ }^{11}$ Locke CJ, Berg RA, Sanders AB, Davis MF, Milander MM, Kern KB, Ewy GA. Bystander cardiopulmonary resuscitation: concerns about mouth-to-mouth. Arch Intern Med 1995; 155: 938-43.

${ }^{12}$ Brenner B, Stark B, Kauffman J. The reluctance of house staff to perform mouth-to-mouth resuscitation in the inpatient setting: what are the considerations? Resuscitation 1994; 28: 185-93.

${ }^{13}$ Brenner B, Kauffman J, Sachter JJ. Comparison of the reluctance of house staff of metropolitan and suburban hospitals to perform mouth-to-mouth resuscitation. Resuscitation 1996; 32: 5-12.

${ }^{14}$ Michael AD, Forrester JS. Mouth-to-mouth ventilation: the dying art. Am J Emerg Med 1992; 10: 156-61.

${ }^{15}$ Bierens JJ, Berden HJ. Basic-CPR and AIDS: are volunteer life-savers prepared for a storm? Resuscitation 1996; 32: 185-91.

${ }^{16}$ Berkowitz LL. Breaking down the barriers: $\mathrm{i}$ mproving physician buy-in of CPR systems. Health Inform 1997; 14: 73-6.

${ }^{17}$ Airway and Ventilation Management Working Group of the European Resuscitation Council. Guidelines for the basic management of the airway and ventilation during resuscitation. A statement by the European Resuscitation Council. Resuscitation 1996; 31: 187-200

${ }^{18}$ Baskett P, Nolan J, Parr M. Tidal volumes which 
are perceived to be adequate for resuscitation. Resuscitation 1996; 31: 231-4

${ }^{19}$ Idris AH. Reassessing the need for ventilation during CPR. Ann Emerg Med 1996; 27: 569-75

${ }^{20}$ Becker LB, Berg RA, Pepe PE, Idris AH, Aufderheide TP, Barnes TA, et al. A reappraisal of mouth-to-mouth ventilation during bystander-initiated cardiopulmonary resuscitation. Resuscitation 1997; 35: 189-201.

${ }^{21}$ Doerges V, Sauer C, Ocker H, Wenzel V, Schmucker P. Smaller tidal volumes during cardiopulmonary resuscitation: comparison of adult and paediatric self-inflatable bags with three different ventilatory devices. Resuscitation 1999; 43: 31-7

${ }^{22}$ Wenzel V, Keller C, Idris AH, Dorges V, Lindner $\mathrm{KH}$, Brimacombe JR. Effects of smaller tidal volumes during basic life support ventilation in patients with respiratory arrest: good ventilation, less risk? Resuscitation 1999; 43: 25-9

${ }^{23}$ Standards for cardiopulmonary resuscitation (CPR) and emergency cardiac care (ECC). JAMA 1974; 227: 833-68.

${ }^{24}$ Standards and guidelines for cardiopulmonary resuscitation (CPR) and emergency cardiac care (ECC). JAMA 1980; 244: 453-509.

${ }^{25}$ Standards and guidelines for Cardiopulmonary Resuscitation (CPR) and Emergency Cardiac Care (ECC). National Academy of Sciences-National Research Council. JAMA 1986; 255: 2905-89.

${ }^{26}$ American Heart Association. Guidelines for Cardiopulmonary Resuscitation Emergency
Cardiac Care. JAMA 1992; 268: 2212-302.

${ }^{27}$ Guidelines for advanced life support: a statement by the Advanced Life Support Working Party of the European Resuscitation Council, 1992. Resuscitation 1992; 24: 111-21.

${ }^{28}$ Guidelines for the basic and advanced management of the airway and ventilation during resuscitation. Resuscitation 1996; 31: 187-230.

${ }^{29}$ Bossaert L. European Resuscitation Council Guidelines for Resuscitation. Amsterdam, Netherlands: Elsevier; 1998.

${ }^{30}$ Guidelines for cardiopulmonary resuscitation and emergency cardiac care. Emergency Cardiac Care Committee and Subcommittees, American Heart Association. JAMA 1992; 268: 2171-295.

${ }^{31}$ Larsen MP, Eisenberg MS, Cummins RO, Hallstrom AP. Predicting survival from out-of-hospital cardiac arrest: a graphic model. Ann Emerg Med 1993; 22: 1652-8.

${ }^{32}$ Swor RA, Jackson RE, Cynar M, Sadler E, Basse E, Boji B, Rivera-Rivera EJ, Maher A, Grubb W, Jacobson R, et al. Bystander CPR, ventricular fibrillation, and survival in witnessed, unmonitored out-of-hospital cardiac arrest. Ann Emerg Med 1995; 25: 780-4.

${ }^{33}$ Becker LB, Ostrander MP, Barrett J, Kondos GT. Outcome of CPR in a large metropolitan area where are the survivors? Ann Emerg Med 1991; 20: 355-61.

${ }^{34}$ Lombardi G, Gallagher J, Gennis P. Outcome of out-of-hospital cardiac arrest in New York City: the pre-hospital arrest survival evaluation (PHASE) study. JAMA 1994; 272: 1573-4. 